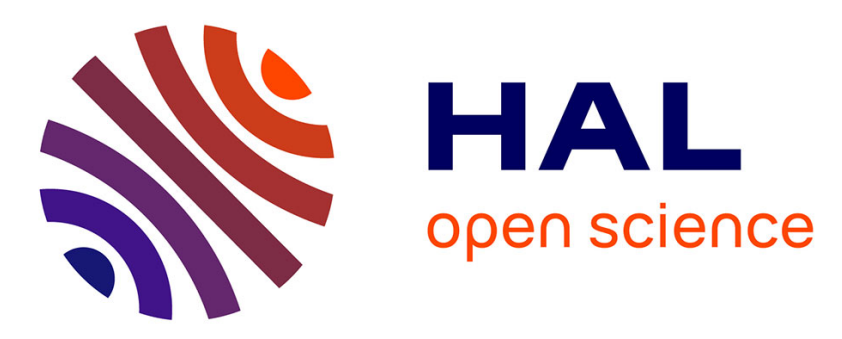

\title{
Free-Radical Carbocyanation of Cyclopropenes: Stereocontrolled Access to All-Carbon Quaternary Stereocenters in Acyclic Systems
}

Nitin S Dange, Frédéric Robert, Yannick Landais

\section{- To cite this version:}

Nitin S Dange, Frédéric Robert, Yannick Landais. Free-Radical Carbocyanation of Cyclopropenes: Stereocontrolled Access to All-Carbon Quaternary Stereocenters in Acyclic Systems. Organic Letters, 2016, 18 (23), pp.6156-6159. 10.1021/acs.orglett.6b03163 . hal-01790866

\section{HAL Id: hal-01790866 https://hal.science/hal-01790866}

Submitted on 14 May 2018

HAL is a multi-disciplinary open access archive for the deposit and dissemination of scientific research documents, whether they are published or not. The documents may come from teaching and research institutions in France or abroad, or from public or private research centers.
L'archive ouverte pluridisciplinaire HAL, est destinée au dépôt et à la diffusion de documents scientifiques de niveau recherche, publiés ou non, émanant des établissements d'enseignement et de recherche français ou étrangers, des laboratoires publics ou privés. 


\title{
Free-radical Carbo-cyanation of Cyclopropenes. A Stereocontrolled Access to All-Carbon Quaternary Stereocenters in Acyclic Systems
}

\author{
Nitin S. Dange, Frédéric Robert, and Yannick Landais* \\ University of Bordeaux, Institute of Molecular Sciences, UMR-CNRS 5255, 351 cours de la libération, 33405 Talence, \\ France.
}

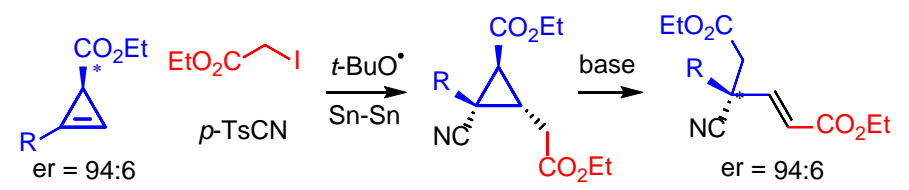

\begin{abstract}
The free-radical carbo-cyanation of cyclopropenes offers straightforward access to tetrasubstituted cyclopropanes in satisfying yields and moderate diastereoselectivity. The incorporation of various functional groups on the cyclopropane ring, allows a subsequent base-mediated ring-opening, leading to functionalized acyclic systems having an all-carbon quaternary stereocenter.
\end{abstract}

Polysubstituted cyclopropanes are useful intermediates in organic synthesis, ${ }^{1}$ which have attracted a lot of interest due mainly to their easy ring opening under acidic-, basic or freeradical conditions. ${ }^{2}$ Cyclopropanes are readily available in enantiopure form using now well-established organometallic and organocatalyzed processes. ${ }^{3}$ Recent progress in the stereocontrolled synthesis of cyclopropanes should also include the functionalization of substituted cyclopropenes. ${ }^{4}$ Organometallic (1) and free-radical additions (2) onto the $\pi$-system of cyclopropenes thus offer a complementary route to polysubstituted cyclopropanes, which may be functionalized further (Figure 1). It is worth of note that cyclopropenes may also be prepared in enantiopure form through rhodium-mediated cyclopropanation of the corresponding alkynes, using commercially available diazo esters. ${ }^{5}$ Recent work by Marek et al. ${ }^{6}$ has elegantly shown that syn-carbometallation of cyclopropenes (Figure 1, eq 1) led to the corresponding metallated cyclopropane $\mathbf{I}$, which could be trapped by various electrophiles or undergo selective ring opening. Free-radical atom-transfer processes using cyclopropenes have been reported earlier by Saicic, ${ }^{7 \mathrm{a}}$ Zard, ${ }^{7 \mathrm{~b}}$ et al. and more recently by Miyata, Ueda et al. ${ }^{8}$ leading to cyclopropanes in moderate to good yields. In contrast, radical addition of two carbon fragments across cyclopropene $\pi$-system has, to our knowledge, not been explored so far. This may be attributed to the high reactivity of the cyclopropyl radical II, which is involved in fast atom-transfer processes (ATRA product IV), ${ }^{9}$ preventing further reaction of II with other radical traps. Steric hindrance in the neighborhood of the radical center may also preclude any approach of reagents onto II. Finally, the weaker nucleophilicity of the cyclopropyl $\sigma$-radical as compared to that of other alkyl radicals is another factor, which may hamper carbo-functionalization of cyclopropenes. ${ }^{10}$

We report here on a new multicomponent carbo-cyanation addition onto substituted cyclopropenes, which gives rise to tetrasubstituted cyclopropyl nitriles III, bearing a quaternary center, in satisfying yields and moderate diastereocontrol. The structure of these cyclopropanes also allow further base-mediated ring opening, offering a straightforward and stereodivergent access to acyclic systems having functionalized all-carbon quaternary stereocenters, present in many biomolecules and natural products.

$$
\text { int: }
$$

Figure 1. Carbometallation and free-radical additions onto cyclopropenes.

Preliminary experiments were carried out using iodoester 1a as a radical precursor, cyclopropene $\mathbf{2} \mathbf{a}$ and commercially available $p$-tosyl cyanide 3 as a cyanide source. Initiation of the process was performed using di-t-butoxyhyponitrite (DTBHN) and $\left(\mathrm{Bu}_{3} \mathrm{Sn}\right)_{2}$ as a chain carrier. ${ }^{11}$ First reaction attempts by mixing the three components, DTBHN and ditin, produced less than $20 \%$ of the desired nitrile as a mixture of two stereoisomers 4 aa and $\mathbf{4 a b}$, in the presence of a large amount of the iodine atom transfer product (not shown). Both diastereomers were easily separated through chromatography and their structure assigned through ${ }^{1} \mathrm{H}$ NMR. Slightly better yield was obtained by adding slowly to the medium, a mixture of $p$-TsCN and DTBHN 
through a syringe pump (Table 1 , entry 1 ). Considering that the atom transfer product (ATRA) (i.e. IV, X = I, Figure 1) was likely the intermediate in the reaction process, it was envisioned that the $\mathrm{Bu}_{3} \mathrm{Sn}$ radical might be sterically too hindered to abstract the iodine atom and regenerate the cyclopropyl radical II for further cyanation. This proved to be the case, as reaction using instead the smaller $\mathrm{Me}_{3} \mathrm{Sn}$ radical led to much improved yield, cyclopropyl nitriles 4aa-4ab being formed in 60\% yield, albeit with modest diastereocontrol (Table 1, entry 2). Reducing the rate of addition had surprisingly a deleterious effect (Table 1 , entry 3). The best yield was observed when DTBHN and $p$ TsCN were added at a rate of $1 \mathrm{ml}$ per hour (Table 1, entry 4). Variation in the nature of the solvent using DCE or $\mathrm{CH}_{3} \mathrm{CN}$ led to a reduced yield as compared to benzene or no conversion (Table 1, entries 5-6). Finally, an attempt at lowering the reaction temperature to $45^{\circ} \mathrm{C}$, instead of $65{ }^{\circ} \mathrm{C}$, to slow down the decomposition of DTBHN, also led to a lower yield (Table 1, entry 7).

Table 1. Optimization of the carbo-cyanation of cyclopropene.

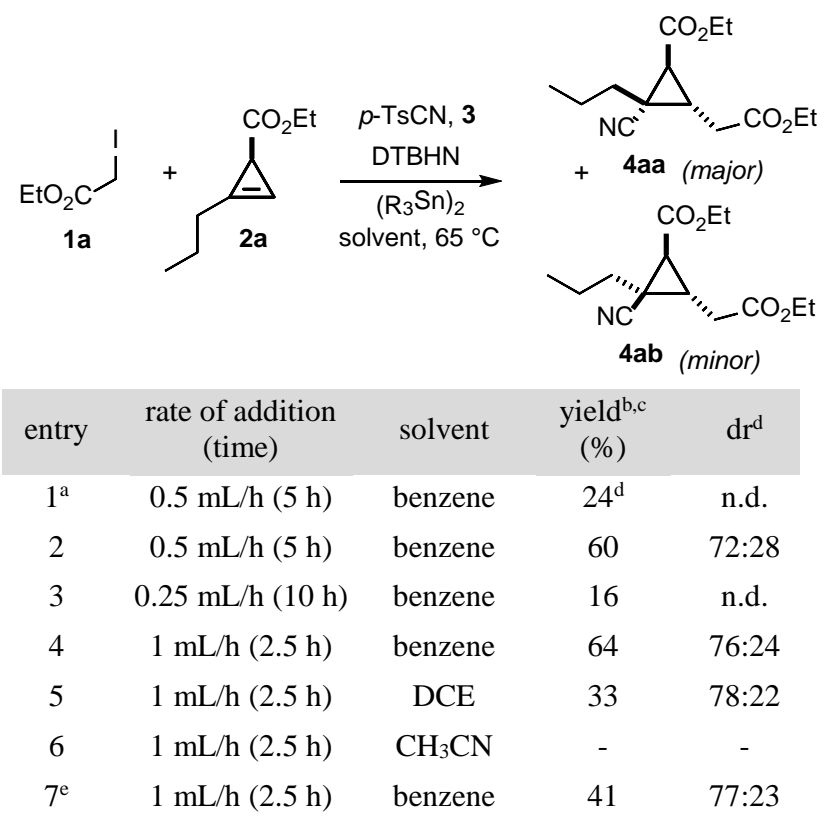

${ }^{a}$ Reaction was carried out mixing 1a (1 equiv), 2 a (2 equiv) and $\left(\mathrm{Me}_{3} \mathrm{Sn}\right)_{2}$ (unless otherwise indicated) (2 equiv) in the solvent, then a mixture of DTBHN (40 mol \%) and 3 (2 equiv) was added at 65 ${ }^{\circ} \mathrm{C}$ through a syringe pump. ${ }^{\mathrm{b}}$ Isolated yields. ${ }^{\mathrm{c}}$ Isolated ATRA product ( 10-15\%). ${ }^{\mathrm{d}}$ Estimated through ${ }^{1} \mathrm{H}$ NMR of the crude reaction mixture after a short filtration column. ${ }^{\mathrm{d}}(\mathrm{Bu} 3 \mathrm{Sn})_{2}$ was used. ${ }^{\mathrm{e}}$ Reaction performed at $45^{\circ} \mathrm{C}$.

Optimized conditions above (Table 1 , entry 4) were then applied to a series of cyclopropenes $\mathbf{2 a - i}$, leading to cyclopropyl nitriles 4a-l in moderate to good yields and modest diastereocontrol (Scheme 1). Variation in yields depending on the nature of the substituents on the cyclopropane ring suggests that steric hindrance is the main issue in this process. For instance, variation of the size of the added ester group (i.e. 1a-c) as in 4a-c led to decreased yield going from $\mathrm{CO}_{2} \mathrm{Et}$ to $\mathrm{CO}_{2} \mathrm{Ph}$. Similarly, increasing bulk of the resident $\mathrm{R}^{2}$ group in cyclopropene as in $\mathbf{4 j - k}$ also led to lower yields and more importantly to a loss of diastereocontrol. In all cases, a small amount of the ATRA product was also isolated (from 10 to $15 \%$ yield). This approach allows an access to orthogonal carbonyl functions as in $\mathbf{4 b} \mathbf{b}-\mathbf{e}$, which will be useful for further functionalizations. Finally, it is worth noticing that, although diastereocontrol is modest, diastereoisomers of $\mathbf{4 b - 1}$ are easily separable through silica gel chromatography.

Scheme 1. Scope of the carbo-cyanation of cyclopropenes 2ai.

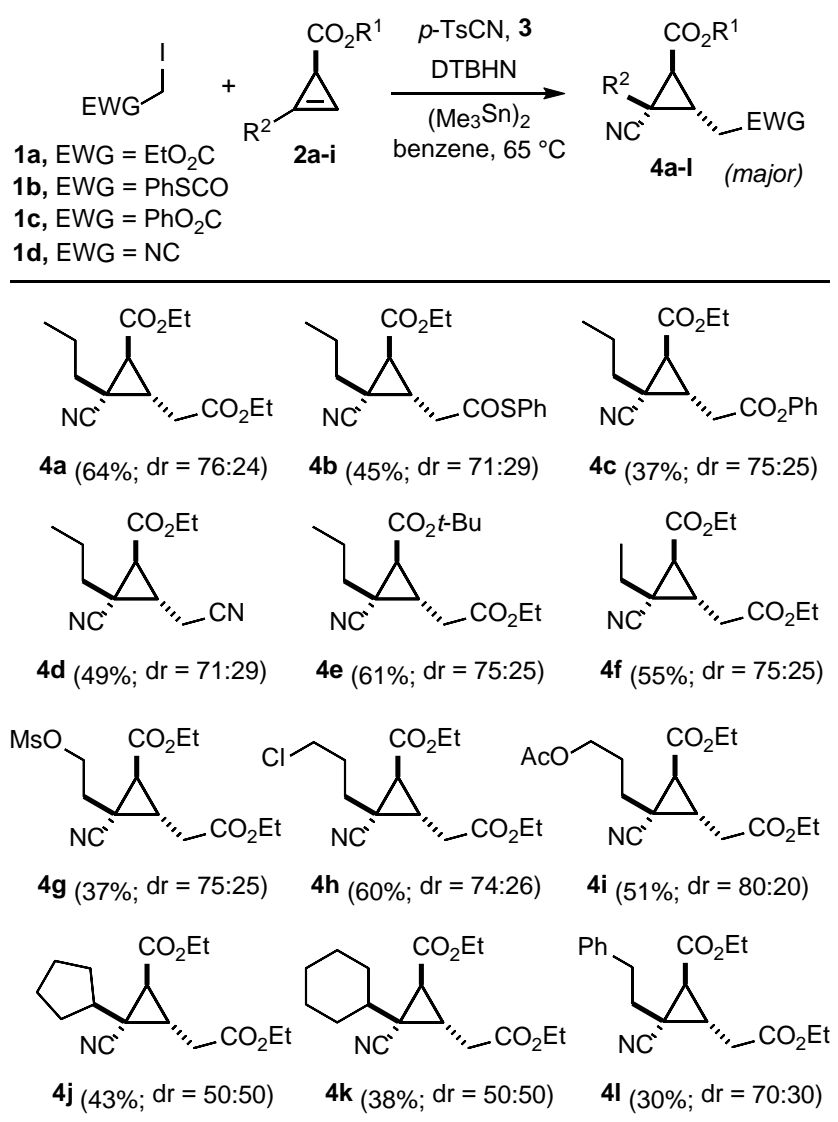

The structure of the two isomers of cyclopropanes 4a-l, assigned through ${ }^{1} \mathrm{H}$ NMR, showed that the addition of the radical precursor occurred anti relative to the cyclopropene ester group, leading to a pyramidalized cyclopropyl $\sigma$-radical, known to rapidly invert $\left(10^{8} \mathrm{~s}^{-1}\right){ }^{10}$ The latter then abstracts the iodine atom of the precursor 1a-d, providing the corresponding ATRA product (i.e. IV, Figure 1) as an intermediate (vide infra). Reaction of this iodide with the trimethyltin radical then returns the cyclopropyl $\sigma$-radical (i.e. II, Figure 1), which may react under two configurations $\mathbf{A}$ and $\mathbf{B}$, the $p$-tosyl cyanide $\mathbf{3}$ preferably approaching anti relative to the resident ester group in configuration $\mathbf{A}$ (Figure 2) ${ }^{8 a}$ Configuration $\mathbf{B}$ is less favored due to steric interactions between the $\mathrm{R}$ group and the $\mathrm{CH}_{2} \mathrm{CO}_{2} \mathrm{Et}$ chain. When $\mathrm{R}$ substituent becomes too bulky as in $\mathbf{4 j} \mathbf{j}-\mathbf{k}$, steric interactions with $\mathrm{CO}_{2}$ Et develop and configurations $\mathbf{A}$ and $\mathbf{B}$ likely have similar energies, resulting in a loss of diastereocontrol. 


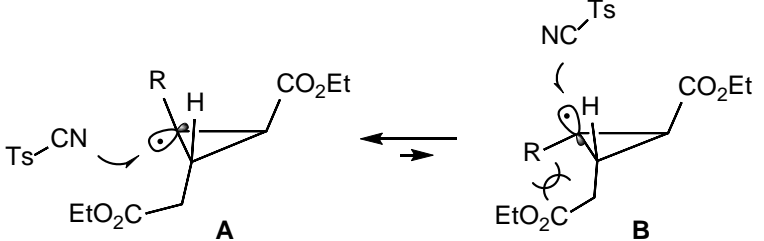

Figure 2. Transition state model for the carbo-cyanation of cyclopropenes.

Interestingly, cyanation of diastereomerically pure iodocyclopropane $\mathbf{5}^{12}$ with $p$-tosyl cyanide $\mathbf{3}$ under the above conditions led to the cyclopropane $\mathbf{4 a}$ with the same diastereomeric ratio observed in the above one-pot reaction, indicating that the inversion at the radical center is faster than the cyanation, in good agreement with earlier studies (Scheme 2). ${ }^{10}$

Scheme 2. Cyanation of iodocyclopropane 5.

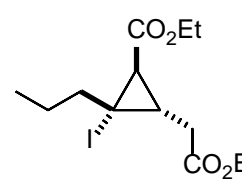

$5(d r>95: 5)$

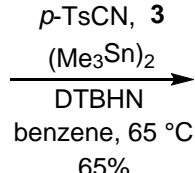

$65 \%$
The high reactivity of the cyclopropyl radical was further illustrated during carbo-cyanation of cyclopropene $\mathbf{6}$. Treatment of the latter under the above carbo-cyanation conditions led to the desired cyclopropyl nitrile $\mathbf{7}$ in low yield along with nitrile 8 (as a mixture of two diastereomers), resulting from a 1,5-hydrogen shift (Scheme 3). This unexpected $\mathrm{C}-\mathrm{H}$ activation is driven by radical stability, secondary radicals being much more stable than cyclopropyl ones, as suggested by radical stabilization enthalpies (RSE), ${ }^{13}$ measured for cyclopropyl and isobutyl radicals.

Scheme 3. 1,5-Hydrogen atom abstraction in carbo-cyanation processes.
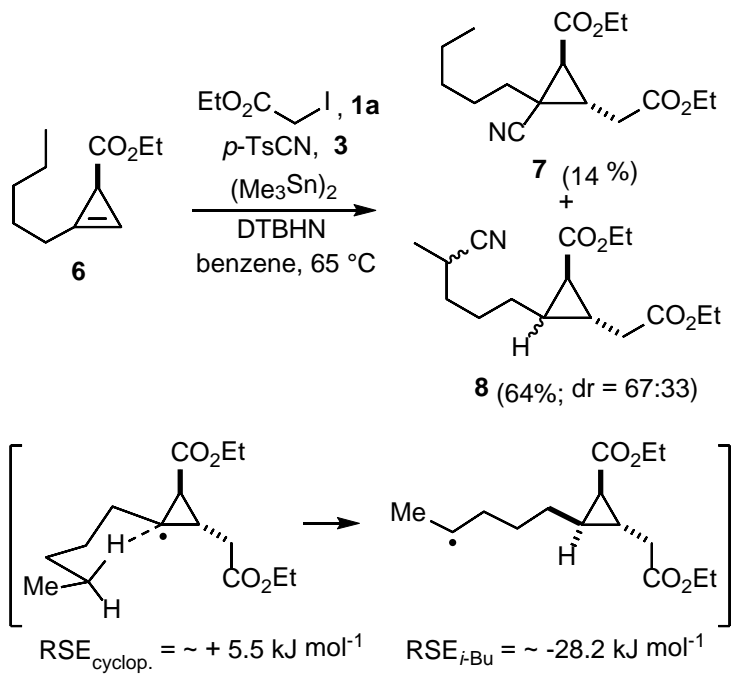

With cyclopropyl nitriles $\mathbf{4}$ in hand, the base-mediated ringopening process was then studied. ${ }^{14}$ Preliminary attempts using LDA led to low conversion and yield. In contrast, soft enolization of the cyclopropanes $\mathbf{4 b}, \mathbf{4 f}$ and $\mathbf{4 h}-\mathbf{i}$ using $i$ $\mathrm{Pr}_{2} \mathrm{NEt}$ (DIPEA) and $\mathrm{MgBr}_{2}$ in $\mathrm{CH}_{2} \mathrm{Cl}_{2}$ was found to be more appropriate, ${ }^{15}$ leading to a clean cyclopropane ring-opening and the formation of highly functionalized acyclic systems 9a-d bearing an all-carbon quaternary center in generally good yields (Scheme 4). ${ }^{16}$ Reaction were relatively fast, except with $\mathbf{9 b}$ where starting material could not be totally consumed even after $12 \mathrm{~h}$.

Scheme 4. Base-mediated ring-opening of cyclopropanes 4b, $4 f$ and $4 h-i$.
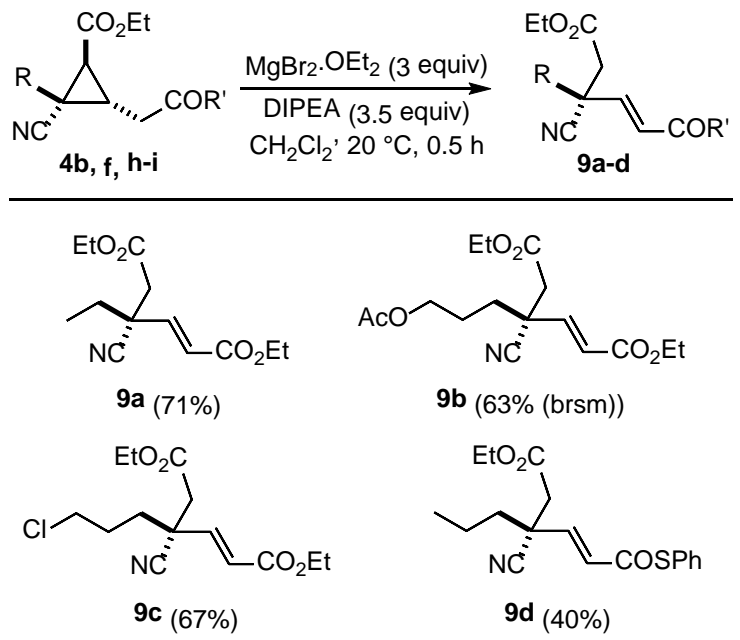

The carbo-cyanation/cyclopropane ring-opening sequence was finally applied to enantioenriched cyclopropene 2a (er 94:6), readily available through cyclopropanation of pent-1yne using Corey's chiral rhodium catalyst (supporting information). ${ }^{5 \mathrm{c}}$ The carbo-cyanation of enantioenriched 2a led to a 7:3 mixture of diastereomers $\mathbf{4 a a}$ and $\mathbf{4 a b}$, which were separated through silica gel chromatography (Scheme 5). Separate treatment of both isomers under the soft enolization conditions above, finally led to enantiomers 10a and 10b, the enantiomeric purity of which was shown (chiral HPLC) to be the same to that of the starting cyclopropene $\mathbf{2 a}$, indicating that no erosion of the enantioselectivity occurred during the whole sequence. This straightforward transformation thus provides a stereodivergent access to both enantiomers of diester $\mathbf{1 0}$ having all-carbon quaternary stereocenters. ${ }^{16}$

Scheme 5. Stereodivergent access to diesters 10a-b having an all-carbon quaternary stereocenter. 


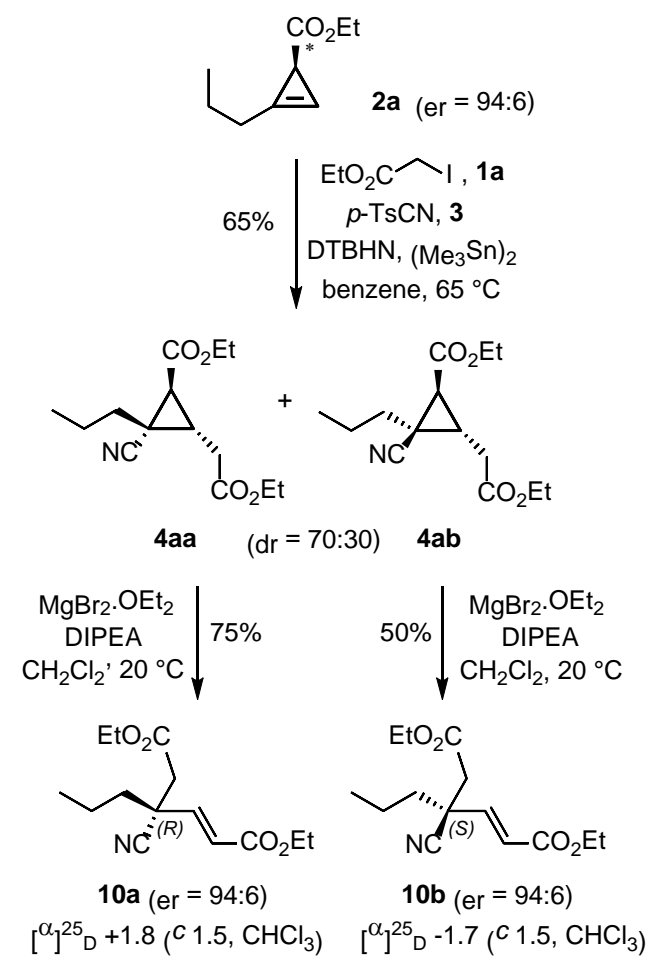

In summary, we reported the first free-radical carbo-functionalization of cyclopropenes. This one-pot multicomponent carbo-cyanation offers a straightforward entry to tetrasubstituted cyclopropanes in satisfying yields and moderate diastereoselectivity. This radical addition installs functionalizations allowing further base-mediated cyclopropane ring-opening, leading to acyclic diesters having an all-carbon quaternary stereocenter. This methodology makes use of readily available enantioenriched cyclopropenes and leads to regioselectivity, which complements those observed in carbo-metallation of cyclopropenes. ${ }^{4,6}$

\section{AUTHOR INFORMATION}

\section{Corresponding Author}

*y.landais@ism.u-bordeaux1.fr

\section{ACKNOWLEDGMENT}

NSD thanks EU for a postdoctoral grant through H2020 Marie-Curie IF program (Leucophyl, $\left.\mathrm{N}^{\circ} 655527\right)$. The University of Bordeaux and CNRS are gratefully acknowledged for financial support. Pierre Bouillac (University of Bordeaux) is thanked for preliminary experiments.

\section{REFERENCES}

(1) (a) Tang, P.; Qin, Y. Synthesis 2012, 44, 2969. (b) Chen, D. Y.K.; Pouwer, R. H.; Richard, J.-A. Chem. Soc. Rev. 2012, 41, 4631. (c) David, E.; Milanole, G.; Ivashkin, P.; Couve-Bonnaire, S.; Jubault, P.; Pannecoucke, X. Chem. Eur. J. 2012, 18, 14904. (c) Taylor, R. E.; Engelhardt, F. C.; Schmitt, M. J. Tetrahedron 2003, 59, 5623. (d) Donaldson, W. A. Tetrahedron 2001, 57, 858. (e) Salaun, J. Chem. Rev. 1989, 89, 124.
(2) (a) Rassadin, V. A.; Six, Y. Tetrahedron 2016, 72, 4701. (b) Marek, I.; Masarwa, A.; Delaye, P.-O.; Leibeling, M. Angew. Chem., Int. Ed. 2015, 54, 414. (c) Schneider, T. F.; Kaschel, J.; Werz, D. B. Angew. Chem., Int. Ed. 2014, 53, 5504. (d) Cavitt, M. A.; Phun, L. H.; France, S. Chem. Soc. Rev. 2014, 43, 804. (e) Yu, M.; Pagenkopf, B. L. Tetrahedron 2005, 61, 321. (f) Burritt, A.; Coron, J. M.; Steel, J. Trends Org. Chem. 1993, 4, 517. (g) Nonhebel, D. C. Chem. Soc. Rev. 1993, 22, 347.

(3) (a) Ford, A.; Miel, H.; Ring, A.; Slattery, C. N.; Maguire, A. R.; McKervey, M. A. Chem. Rev. 2015, 115, 9981. (b) Charette, A. B. in Comprehensive Organic Synthesis (2nd Ed.) Eds Knochel, P.; Molander, G. A. 2014, 4, 1054. (c) Charette, A. B.; Lebel, H.; Roy, M.-N. In Copper-Catalyzed Asymmetric Synthesis, Eds Alexakis, A.; Krause, N.; Woodward, S. 2014, 203. (d) Reissig, H.-U. Angew. Chem., Int. Ed. 1996, 35, 971. (e) Bartoli, G.; Bencivenni, G.; Dalpozzo, R. Synthesis 2014, 46, 979. (f) Concellon, J. M.; Rodriguez-Solla, H.; Concellon, C.; del Amo, V. Chem. Soc. Rev. 2010, 39, 4103. (g) Pellissier, H. Tetrahedron 2008, 64, 7041. (h) Lebel, H.; Marcoux, J.-F.; Molinaro, C.; Charette, A. B. Chem. Rev. 2003, 103, 977. (i) Connon, S. J. Synlett 2009, 354.

(4) (a) Rubin, M.; Rubina, M.; Gevorgyan, V. Chem. Rev. 2007, 107, 3117. (b) Zhu, Z.-B.; Wei, Y.; Shi, M. Chem. Soc. Rev. 2011, 40, 5534. (c) Archambeau, A.; Miege, F.; Meyer, C.; Cossy, J. Acc. Chem. Res. 2015, 48, 1021. (d) Vicente, R. Synthesis 2016, 48, 2343.

(5) (a) Protopopova, M. N.; Doyle, M. P.; Müller, P.; Ene, D. J. Am. Chem. Soc. 1992, 114, 2755. (b) Doyle, M. P.; Ene, D. G.; Peterson, C. S.; Lynch, V. Angew. Chem. Int. Ed. 1999, 38, 700. (c) Lou, Y.; Horikawa, M.; Kloster, R. A.; Hawryluk, N. A.; Corey, E. J. J. Am. Chem. Soc. 2004, 126, 8916. (d) Goto, T.; Takeda, K.; Shimada, N.; Nambu, H.; Anada, M.; Shiro, M.; Ando, K.; Hashimoto, S.-I. Angew. Chem. Int. Ed. 2011, 50, 6803. (e) Boruta, D. T.; Dmitrenko, O.; Yap, G. P. A.; Fox, J. M. Chem. Sci. 2012, 3, 1589. (f) Cui, X.; Xu, X.; Lu, H.; Zhu, S.; Wojtas, L.; Zhang, X. P. J. Am. Chem. Soc. 2011, 133, 3304.

(6) (a) Minko, Y.; Marek, I. Chem. Commun. 2014, 50, 12597. (b) Zhang, F.-G.; Eppe, G.; Marek, I. Angew. Chem. Int. Ed. 2016, 55, 714. (c) Roy, S. R.; Didier, D.; Kleiner, A.; Marek, I. Chem. Sci. 2016, 7, 5989. (d) Müller, D. S.; Marek, I. Chem. Soc. Rev. 2016, 46, 4552.

(7) (a) Ferjancic, Z.; Cekovic, Z.; Saicic, R. N. Tetrahedron Lett. 2000, 41, 2979. (b) Legrand, N.; Quiclet-Sire, B.; Zard, S. Z. Tetrahedron Lett. 2000, 41, 9815. (c) Yamago, S.; Ejiri, S.; Nakamura, E. Chem. Lett. 1994, 1889.

(8) (a) Ueda, M.; Doi, N.; Miyagawa, H.; Sugita, S.; Takeda, N.; Shinada, T.; Miyata, O. Chem. Commun. 2015, 51, 4204. (b) Doi, N.; Takeda, N.; Miyata, O.; Ueda, M. J. Org. Chem. 2016, 81, 7855.

(9) For instance $\mathrm{BrCCl}_{3}$ bromine atom transfer to a cyclopropyl radical was estimated to occur with a rate constant of $2.8 \times 10^{9} \mathrm{M}^{-1} \mathrm{~S}^{-1}$. See: Johnston, L. J.; Scaiano, J. C.; Ingold, K. U. J. Am. Chem. Soc. 1984, 106, 4877.

(10) Walborsky, H. M. Tetrahedron 1981, 37, 1625.

(11) (a) Ovadia, B.; Robert, F.; Landais, Y. Chimia 2016, 70, 34. (b) Liautard, V.; Robert, F.; Landais, Y. Org. Lett. 2011, 13, 2658.

(12) Iodocyclopropane 5 was obtained in $87 \%$ yield (dr 88:12) through addition of $\alpha$-iodoester $\mathbf{1 a}$ onto $2 \mathbf{a}$ using $\left(\mathrm{Bu}_{3} \mathrm{Sn}\right)_{2}(50 \mathrm{~mol} \%)$ and DTBHN (10 mol \%).

(13) Hioe J.; Zipse, H. Encyclopedia of Radicals in Chemistry, Biology and Materials, 2012, John Wiley \& Sons, Ltd.

(14) (a) Mead, K. T.; Lu, J. Tetrahedron Lett. 1994, 35, 8947. (b) Sasaki, M.; Kondo, Y.; Nishio, T.; Takeda, K. Org. Lett. 2016, 18, 3858.

(15) Zhou, G.; Lim; D.; Coltart, D. M. Org. Lett. 2008, 10, 3809.

(16) (a) Trost, B. M.; Jiang, C. Synthesis 2006, 369. (b) Hong, A. Y.; Stoltz, B. M. Eur. J. Org. Chem. 2013, 2745. (c) Quasdorf, K. W.; Overman, L. E. Nature, 2014, 516, 181. 
